\title{
Unsaturated Polyesters / Layered Silicate Nanocomposites: Synthesis and Characterization
}

\author{
M. A.Motawie ${ }^{1}$,N.M.Ahmed ${ }^{1}$,S.M.ElMesallamy ${ }^{1}$, E.M.Madek ${ }^{1}$, N.G.Kandile ${ }^{2 *}$ \\ ${ }^{1}$ Egyptian Petroleum Research Institute, EPRI, Cairo, Egypt \\ ${ }^{2}$ Chemistry Department, Faculty of Women, Ain Shams University, Cairo, Egypt \\ ${ }^{*}$ Corresponding author
}

\begin{abstract}
Unsaturated polyester (PEs) / Egyptian bentonite nanocomposites were prepared. The bentonites used were chemically modified by cation exchange reactions with surfactant (quaternary ammonium salt). The prepared nanocomposites were characterized by morphology analysis using X-ray diffraction, transmition electron microscope, thermal analysis, mechanical analysis and electrical analysis. The results reported in this study revealed the improvement of the thermal and mechanical properties of the prepared nanocomposites. All modified clay-polyester nanocomposites displayed improved mechanical properties with organoclay content up to $7 \mathrm{wt} \%$ as compared with PEs filled with micrometer clay (40 wt \%). Also the prepared nanocomposites show improvement of thermal stability and electrical conductivity .
\end{abstract}

Keywords: Unsaturated polyesters, Organoclay, Nanocomposites, Egyptian Bentonite (EB), Mechanical properties.

\section{Introduction}

Polymer matrix based nanocomposites have received enormous attention both in academia and industry over the past decades. Polymer/ clay nanocomposites are a new class of composites with polymer matrix in which the dispersed phase is the silicate constituted by particles that have at least one of its dimensions in the nanometer range $\left(10^{-9} \mathrm{~m}\right)$. The excellent properties of nanocomposites are attributed to the large surface to volume ratio of the nanofillers [1]. Nanocomposites can, in principle, be formed from clays and organoclay in a number of ways including various in situ polymerization [2, 3, 4-10],solution [11,12], and latex [13,14] methods.

Much attention has been directed toward the preparation of unsaturated polyester (UP) / montmorillonite (MMT) nanocomposite. Two steps were used for preparing unsaturated polyester-layered silicate nanocomposite. In the first step, pre-intercalates of the unsaturated polyester and MMT nanocomposites, in other words, mixture of the UP and organophilic-treated MMT are prepared in the first step; a styrene monomer was then added to the pre-intercalates of UP/MMT with varying mixing time [15]. However the unsaturated polyester (UP)/organically modified clay (OMC) nanocomposites were prepared by multistep simultaneous mixing of UP oligomer chain, styrene (St) monomer, and OMC [16], the intercross-linked networks of unsaturated polyester (UP) toughened epoxy-clay hybrid nanocomposites have been developed. Epoxy resin (DGEBA) was toughened with 5, 10 and 15\% (by wt) of unsaturated polyester using benzoyl peroxide as radical initiator and 4, 4'-diaminodiphenylmethane as a curing agent at appropriate conditions [17]. Dhakal et al, investigate the effect of various loading levels of nanoclay reinforcement on the nanomechanical properties of layered silicate nanoclay reinforced unsaturated polyester (UPE) nanocomposites using nanoindentation test method [18]. Various forms of organically modified montmorillonite (OMMT) were introduced in situ during the copolyaddition of epichlorohydrin, maleic anhydride and phthalic anhydride. The catalytic effect of OMMT containing quaternary ammonium ions was observed the introduction of clay leads to the increase in softening temperature, as well as melt or solution viscosity of unsaturated polyester [19]. The reaction between unsaturated polyester (UP) resin and styrene (St) is a heterogeneous free-radical chain-growth cross-linking copolymerization. Curing of the UP/St system in the presence of organically-modified nanoclay was studied by differential scanning calorimetry (DSC) and Fourier transform infrared (FTIR) spectroscopy. A mechanistic kinetic model based on the free radical copolymerization mechanism was developed to simulate the reaction rate and conversion profiles of UP/St resin mixtures with various nanoclay contents cured at low temperatures [20]. Unsaturated polyester (UP)/montmorillonite (MMT) nanocomposite was prepared by using hydroxylpropylacrylate (HPA) as a reactive diluent instead of conventional styrene monomer and the effect of polarity of reactive diluent on properties of nanocomposite was investigated ${ }^{[21]}$. The addition of a small amount of nanoclay (1-3 wt \%) can provide excellent volume shrinkage control of unsaturated polyester (UP)/styrene (St)/poly (vinyl acetate) (PVAc) systems cured at room temperature. PVAc serves as the low profile additive (LPA) [22]. The reinforcing effect of both delaminated and intercalated clay nanoplatelets was theoretically evaluated with the Halpin-Tsai equations. It was evaluated that the aspect ratio of delaminated clay 
nanoplatelets was approximately 150 . The increase of the storage modulus below and above the glass transition temperature was achieved without reducing glass transition temperature and Izod impact strength with increasing clay content [23]. The bentonite used was unmodified and with different chemical treatments. The effects of these different chemical modifications (cation exchange reactions with quaternary ammonium and phosphonium salts) of this clay as well as the effect of clay content on the thermal, barrier (water absorption), mechanical (flexural) and dynamic-mechanical properties of unsaturated polyester matrix were analyzed. The results clearly show that the chemical modifications of the clay cause a desired effect on its final properties improving the performance of the nanocomposites. The enhancements could be directly related to the dispersion of the clay inside the matrix, as shown by transmission electron microscopy [24]. The thermal stability of nanocomposites based on unsaturated polyester resin (UP) and montmorillonite (MMT) clays was reported. The coefficients of thermal expansion (CTE) of both neat resin and nanocomposites with various concentrations of MMT were measured and it was found that the incorporation of clay particles reduced the CTE of the polyester resin [25]. The curing behavior of unsaturated polyester/modified montmorillonite nanocomposites was studied by Yan Zhou et al [26]. The results showed that their gel times increased markedly at the same cure temperature, and that the activation energy of the nanocomposites was higher than that of the pure unsaturated polyester. The effects of organic modifications of the pristine clay on the UV-curing behavior and structure of the nanocomposites system were investigated. The organic modifications of the clay affected considerably the UVcuring behavior and structure of the nanocomposite system [27]. The mechanical properties, the tensile modulus, tensile strength, flexural modulus, flexural strength and impact strength of the composites with modified montmorillonite were higher than the corresponding properties of the composites with unmodified montmorillonite. The tensile modulus, tensile strength, flexural modulus and flexural strength values showed a maximum, whereas the impact strength exhibited a minimum at approximately 3-5 wt $\%$ modified montmorillonite content. These results imply that the level of exfoliation may also exhibit a maximum with respect to the modified montmorillonite content. The level of improvement in the mechanical properties was substantial. Adding only $3 \mathrm{wt} \%$ organically modified clay improved the flexural modulus of unsaturated polyester by $35 \%$. The tensile modulus of unsaturated polyester was also improved by $17 \%$ at $5 \%$ of organically modified clay loading [28].

The objective of this study is to enhance the performance of polymer nanocomposites using the polyesters PEs based on maleic anhydride and dimethyl terephthalate with different concentrations of ethylene glycol EG with organo clay. Therefore, the present work investigates the mechanical properties and thermal stability of PEs-MMT nanocomposites. The results are supported by mechanical testing, X-ray diffraction (XRD), transmission electron microscopy (TEM), and thermo gravimetric analysis (TGA).

\section{Materials}

\section{Experimental}

Egyptian Bentonite Clay (EB), is supplied from south of El-Hamamm district, grinding through ballmill and saving at 0.6 micron. ethylene glycol (EG), El-Nasr Pharmaceutical Co., Para toluenesulphonic Acid, Sigma Aldrich Co., Dimethyl Terephthalate (DMT), Sigma Aldrich Co., Maleic anhydride (MA), Sigma Aldrich Co., Octadecylamine (ODA), Faluca Sigma Aldrich Co., Methyl Ethyl Ketone Peroxide (MEKP), Fluka Chemika,. Styrene, Sigma Aldrich, CO., Cobalt Octoate,El-Nasr Pharmaceutical Chemicals Co., and Hydroquionon, El-Nasr Pharmaceutical Chemicals Co. all chemical were used without further purifications.

\section{Instrumentation}

Morphology analysis . X-ray diffraction (XRD) patterns were obtained using a Rigaku X-ray diffractometer equipped with CuKa radiation and a curved graphite crystal monochromator. Samples were prepared by applying the pre-intercalated mixture and nanocomposite of UP-MMT in sheet form on a slide. All XRD data were collected with an X-ray generator $(\lambda=1.5406 \AA)$. Bragg's law $(\lambda=2 \mathrm{~d} / \operatorname{Sin} \Theta)$ was used to compute the crystallographic $\mathrm{d}$-spacing. The TEM pictures were performed by TEM-1230 with an accelerating voltage of 100KV (JEOL Co.,Japan).

Thermal analysis: Thermal stability was determined by the thermogravimetric analysis (TGA) with Shimadzu TGA-50H thermal analyzer in nitrogen atmosphere and at a heating rate of $10^{\circ} \mathrm{C} / \mathrm{min}$ from $800^{\circ} \mathrm{C}$.

Mechanical analysis: Mechanical measurments (i.e tensile strength, elongation at break) were determined with an Instron 1026 testing machine, according to ASTM-D638, 08. The hardness of test specimens was measured with shore D durometer according to ASTM-D2240-05. All these tests were performed at room temperature (25 $\pm 1^{\circ} \mathrm{C}$ ) and the reported results were averaged from a minimum of five specimens.

Electrical analysis: Electrical conductivity dc of the prepared cast sampels was performed using the Keilhley Electrometer Model 6517A/ High Resistance Meter by applying the following equation: Specific resistivity = (R.S)/ $\mathrm{h}$ where $\mathrm{R}$ is the electrical resistance measured directly by the used apparatus, $\mathrm{h}$ and $\mathrm{S}$ are the sample thickness and area, respectively. 


\section{Synthesis of different composites PEEG $_{1}$ and PEEG2}

\section{Synthesis of unsaturated polyester based on maleic anhydride PEEG $_{1}$}

Dimethyl terephthalate $(19.4 \mathrm{~g}, 100 \mathrm{ml})$, maleic anhydride ( $9.8 \mathrm{~g}, 100 \mathrm{ml})$, ethylene glycol $(12.4 \mathrm{~g}, 200$ $\mathrm{ml})$ and $\mathrm{p}$-toluensulfonic acid $(0.21 \mathrm{~g}, 0.5 \% \mathrm{wt})$ as a catalyst were charged into a three necked round bottom flask $250 \mathrm{ml}$ fitted with a Dean-stark tube, reflux condenser, thermometer and nitrogen inlet tube. The flask was heated slowly at $150{ }^{\circ} \mathrm{C}$ under a gentle nitrogen stream with continuous magnetic stirring for $30 \mathrm{~min}$; the temperature was raised from $180-200^{\circ} \mathrm{C}$ for $6-8 \mathrm{hrs}$, to ensure that water was completely eliminated during this period. The resulted resin was dissolved in styrene monomer within $40 \%$ wt of resin to introduced pale yellow polyester resin. Then hydroquinone was added as inhibitors to the resin.

\section{Synthesis of unsaturated polyester based on ethylene glycol PEEG2}

In $100 \mathrm{ml}$ beaker $(20 \mathrm{gm})$ unsaturated polyester prepolymer and $2 \mathrm{gm}(10 \%)$ of ethylene glycol were sonicated at $30^{\circ} \mathrm{C}$ for $20 \mathrm{~min}$, the new resin was poured in Petri dish then $0.05 \%$ of MEKP (Methyl ethyl ketone peroxide) was added as curing agent and cobalt octoate as initiator at room temperature to produce $\mathrm{PEEG}_{2}$ film.

\section{Preparation of Organo-Bentonite}

The organo-bentonites were synthesized by cation exchange reaction between Na-bentonite and surfactant i.e octadecylamine (ODA)[29]. The surfactant was protonated by adding $\mathrm{HCl}$. Aqueous suspension $0.5 \mathrm{wt} \%$ of Na-bentonite was prepared and heated at $80^{\circ} \mathrm{C}$. The prepared alkyl ammonium salt solution was drop wise added to the Na-bentonite suspension and maintained at $80{ }^{\circ} \mathrm{C}$ for $12 \mathrm{~h}$ under vigorous stirring. Then the suspension was cooled to room temperature. Finally, the treated clay particles were collected by centrifugation and subsequently washed with deionized water several times until no halide were detected in the filtrate by $\mathrm{AgNO} 3$ test. The dispersion and washing was accomplished using a 50/50 ethanol/water mixture. The filter cake was then placed in a vacuum oven at $80{ }^{\circ} \mathrm{C}$ for $24 \mathrm{~h}$. The dried cake was grind and screened with a 325 -mesh sieve to obtain the inorganic-organophilic material ODA-B.

\section{Preparation of PEEG1Composites}

A series of PE / Egyptian Bentonite (EB) composites were prepared by sonicatore with the following molar ratio $3,5,7,10,20,30,40,50$, and $60 \%$ wt.

In $100 \mathrm{ml}$ beaker $(20 \mathrm{gm})$ unsaturated polyester prepolymer and $(0.66 \mathrm{gm})$ of EB was sonicated at $30{ }^{\circ} \mathrm{C}$ for $40 \mathrm{~min}$, the composite resin was poured in Petri dish then $0.05 \%$ of MEKP (Methyl ethyl ketone peroxide) was added as curing agent and cobalt octoate as initiator at room temperature to produce PEEG1 / EB composites.

\section{Preparation of PEEG1 Nanocomposites}

A series of PE / Organo-Bentonite (OB) nanocomposites were prepared by sonicatore with the following molar ratio $3,5,7$, and $10 \% \mathrm{wt}$.

In $100 \mathrm{ml}$ beaker $(20 \mathrm{gm})$ unsaturated polyester prepolymer and [0.66 gm (3\%)]of OB was sonicated at $30{ }^{\circ} \mathrm{C}$ for $40 \mathrm{~min}$, the nanocomposite resin was poured in Petri dish then we add $0.05 \%$ of MEKP ( Methyl ethyl ketone peroxide ) as curing agent and cobalt octoate as initiator at room temperature to introduced PEEG1 / OB nanocomposites.

\section{Preparation of PEEG2 Composites}

A series of PEEG2 / Egyptian Bentonite (EB) composites were prepared by sonicatore with the following molar ratio $3,5,7,10,20,30,40,50$, and $60 \%$ wt.

In $100 \mathrm{ml}$ beaker $(20 \mathrm{gm})$ unsaturated polyester prepolymer, [2 gm (10\%)] of ethylene glycol (EG) and ( $0.66 \mathrm{gm}$ ) of EB was sonicated at $30{ }^{\circ} \mathrm{C}$ for $40 \mathrm{~min}$, the composite resin was poured in Petri dish then add $0.05 \%$ of MEKP (Methyl ethyl ketone peroxide) as curing agent and cobalt octoate as initiator at room temperature to introduced PEEG2 / EB composites.

\section{Preparation of PEEG2 Nanocomposites}

A series of PEEG2 / Organo-Bentonite (OB) nanocomposites were prepared by sonicatore with the following molar ratio $3,5,7$, and $10 \% \mathrm{wt}$.

In $100 \mathrm{ml}$ beaker $(20 \mathrm{gm})$ unsaturated polyester prepolymer, [2 gm (10\%)] of ethylene glycol (EG) and [0.66 gm ( $3 \%)$ ] of OB was sonicated at $30{ }^{\circ} \mathrm{C}$ for $40 \mathrm{~min}$. the nanocomposite resin was poured in Petri dish then add $(0.05 \%)$ of MEKP (Methyl ethyl ketone peroxide) as curing agent and cobalt octoate as initiator at room temperature to introduced $\mathrm{PEEG} 2 / \mathrm{OB}$ nanocomposites. 


\section{Results and Discussions}

In this study polyesters (PE) based on maleic anhydride and dimethylterephathalte with different concentrations of ethylene glycol EG were prepared to give two polyesters $\mathrm{PEEG}_{1}$ and $\mathrm{PEEG}_{2}$. A series of PEEG1, PEEG2 / Egyptian Bentonite (EB) composites were prepared by sonicatore with the following molar ratio $3,5,7,10,20,30,40,50$, and $60 \%$ wt., also series of PEEG1,PEEG2 / Organo-Bentonite (OB) nanocomposites were prepared by sonicatore with the following molar ratio $3,5,7$, and $10 \%$ wt. to investigate the mechanical properties and thermal stability of the prepared composites.

\section{Structure studies}

\section{Morphology Analysis}

XRD pattern Fig.1a,b of the inorganic clay has a peak at a $2 \theta$ value of $7 \circ$ and that corresponds to an intergallery spacing of $1.26 \mathrm{~nm}$. The composites prepared with this clay also have this peak and that indicates the existence of clay as microtactoids and that leads to the formation of clay filled composites.

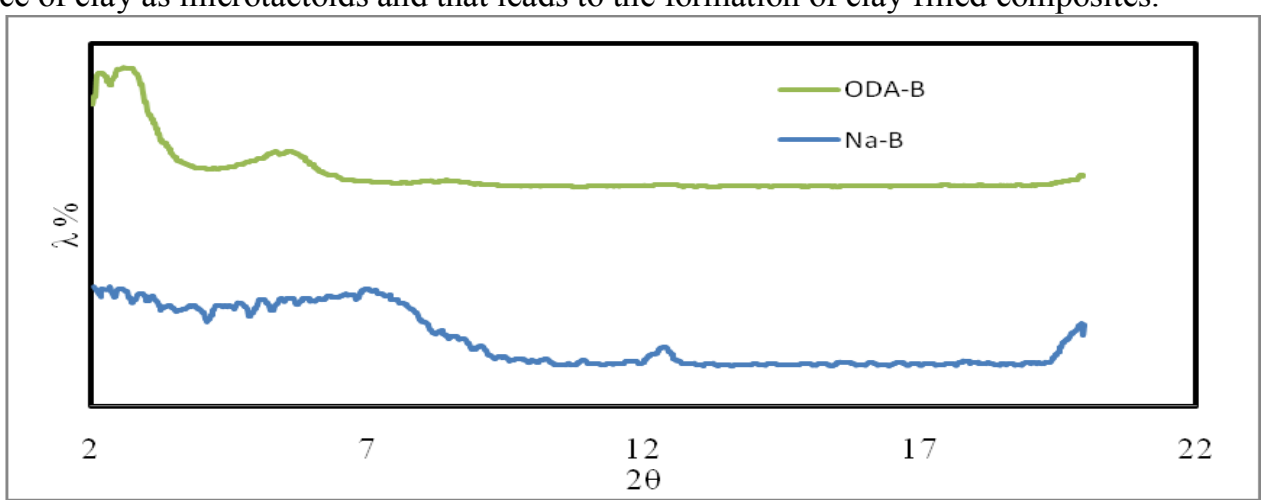

Fig 1a. XRD of Egyptian Bentonite (Na-B) \& Organo Egyptian Bentonite (ODA-B).

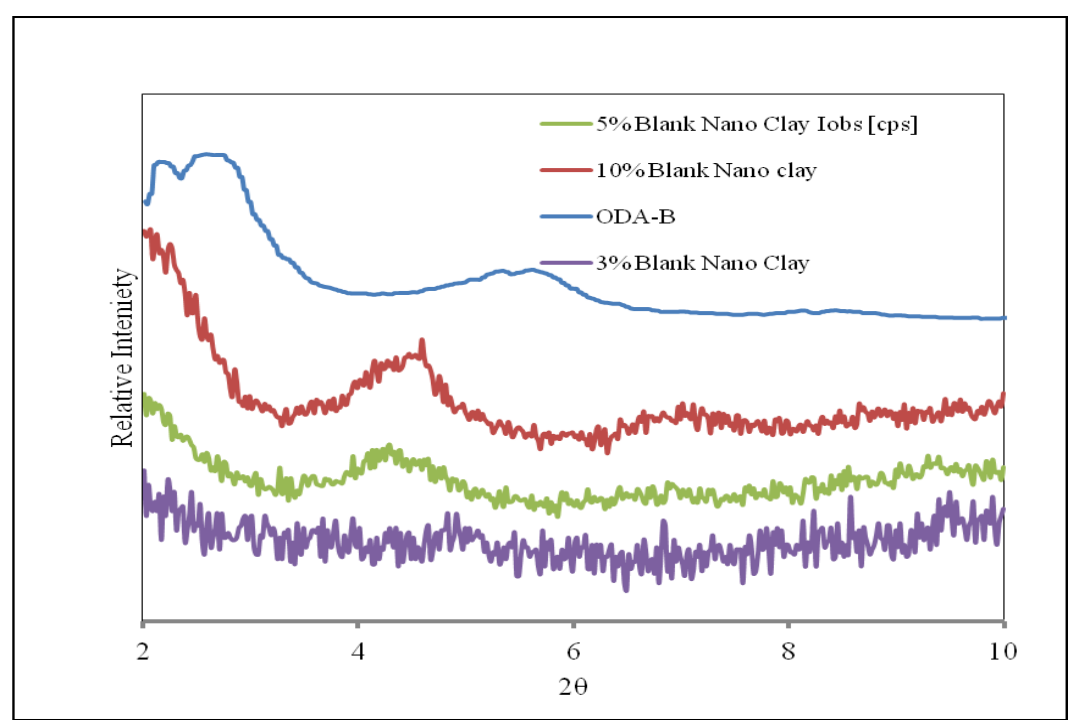

Fig 1b: XRD of different wt \% of ODA-B. 3, 5, and 10\% in PEEG1 matrix.

Organic clay has a peak at $2 \theta$ value of $2.9^{\circ}$ and the corresponding initial intergallery spacing is $3.09 \mathrm{~nm}$ also another characteristic peak at $2 \theta=5.7^{\circ}$ with intergallery spacing is $1.55 \mathrm{~nm}$. This peak is not present in the nanocomposites prepared with organoclay Fig.2. 


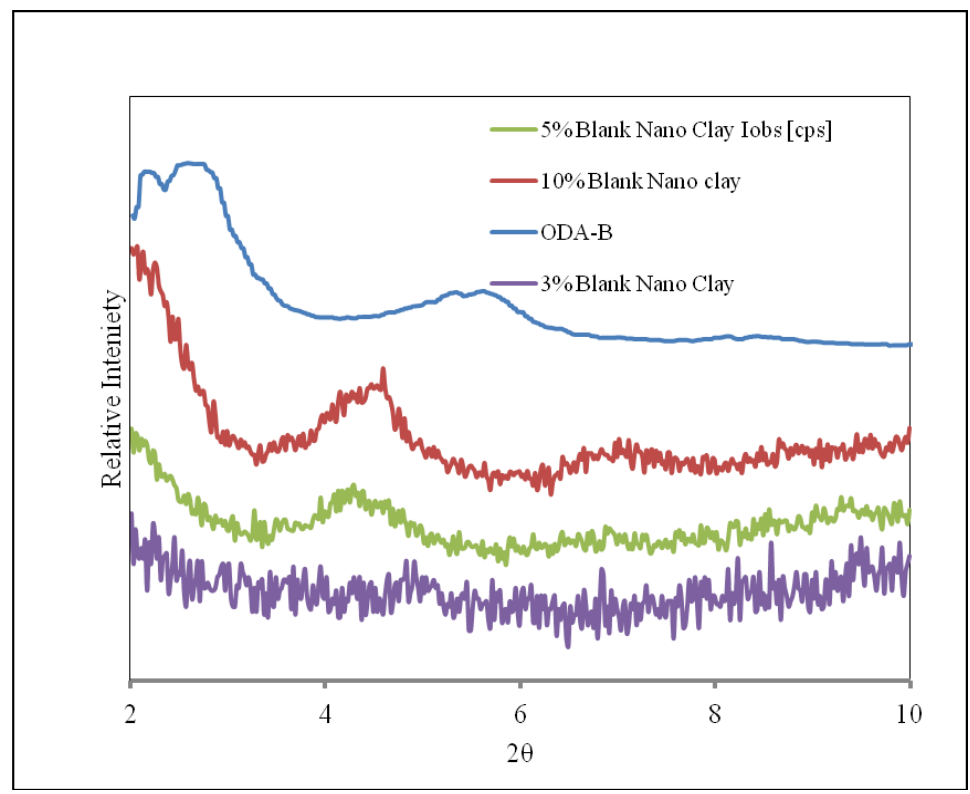

Fig 2: XRD of different wt \% of ODA-B. 3, 5, and 10\% in PEEG1 matrix .

During shear mixing, the polymer intercalates between the intergallery spacing of organoclay and makes the clay layers to move apart. On further mixing the nanosize clay platelets disperse fully in the unsaturated polyester matrix. The disappearance of peak indicates the separation of clay layers and the formation of exfoliated nanocomposite. For the organoclay content of $7 \& 10 \mathrm{wt}$. \%, there is a broad peak at $2 \theta$ value of $4.6^{\circ}$ and $4.6^{\circ}$ the corresponding intergallery spacing is $19.12 \mathrm{~A}^{\circ}$ and $19.42 \mathrm{~A}^{\circ}$ respectively. This indicates the formation of intercalated nanocomposites.

On the other hand, TEM allows a qualitative understanding of the internal structure and can directly provide information in real space, in a localized area, on morphology and defect structures [30, 31]. Since the silicate layers are composed of heavier elements $(\mathrm{Al}, \mathrm{Si}$ and $\mathrm{O})$ than the interlayer and surrounding matrix $(\mathrm{C}, \mathrm{H}$ and $\mathrm{N}$ ), they appear darker in bright-field images. Therefore, when nanocomposites are formed, the intersections of the silicate sheets are seen as dark lines which are the cross sections of the silicate layers, measuring $1 \mathrm{~nm}$ thick. However, special care must be exercised to guarantee a representative cross-section of the sample [30, 32].

Fig 3a.b show the TEM micrographs obtained for an intercalated and an exfoliated nanocomposite. As already mentioned, besides these two well defined structures other intermediate organizations can exist presenting both intercalation and exfoliation. In this case, a broadening of the diffraction peak is often observed and one must rely on TEM observation to define the overall structure [33] so more direct evidence for the formation of a nanocomposite is provided by TEM

The TEM of image 3\%ODA/PEEG1 in Fig 3c display individual silicate layers apparent as dark lines. However, the 5\%ODA/PEEG2 in Fig.3d layers have some irregular dispersions of the silicate layer maintained their original ordering.
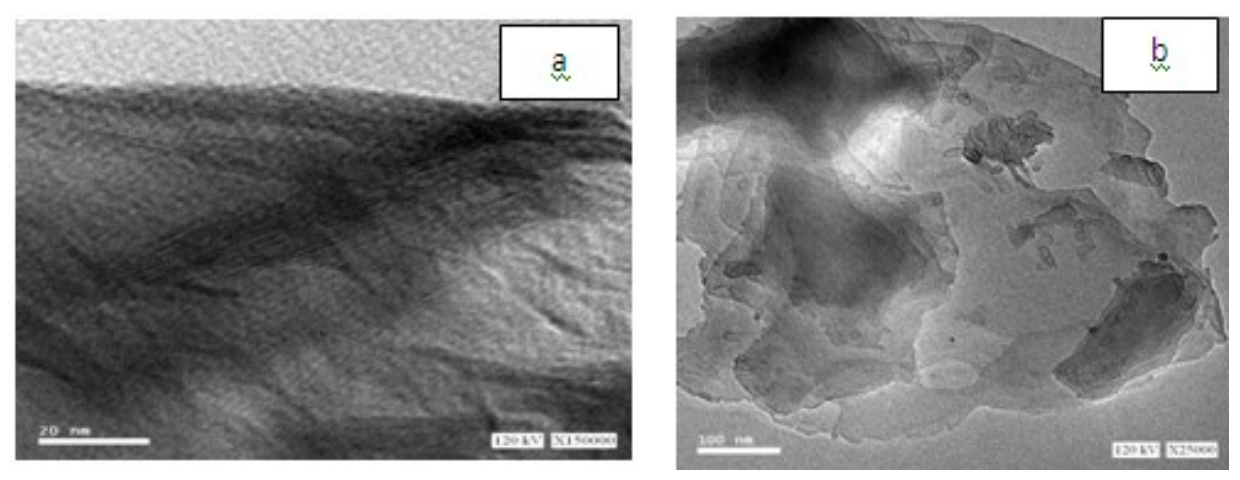

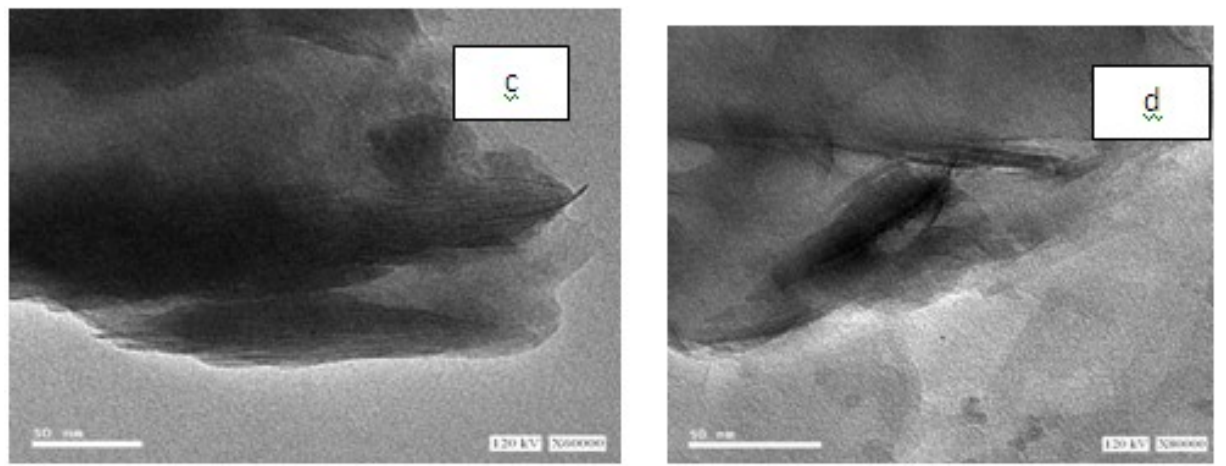

Fig 3: TEM of a) 3\% Organo Egyptian Bentonite (ODA) in PEEG1 matrix, b) 5\% Organo Egyptian Bentonite (ODA) PEEG1 matrix, c) 3\% Organo Egyptian Bentonite (ODA) PEEG2 matrix, d) 5\% Organo Egyptian Bentonite (ODA) PEEG2 matrix.

\section{Thermal Analysis}

The behavior of polymer/clay nanocomposites is complicated and many factors contribute to increase in thermal resistance. Due to characteristic structure of layers in polymer matrix and nanoscopic dimensions of filler particles, several effects have been observed that can explain the changes in thermal properties. The TGA thermogram Figs 4,5 shows the effect of the clay content on the stability of PE nanocomposites where the char yield in PE was 4.8 while in case of $7 \%$ it becomes 8.6 as demonstrated in Table 1 . The PEEG2 nanocomposites sampels have thermal stability and char yield more than the other samples, where the char yield was 7.6 and 11 in PEEG2 and 7\% PEEG2 respectively. Where the particles with nanometer size restrict segmental motion near the organic-inorganic interface. This is a typical effect for the inclusion of clay in a polymer system.

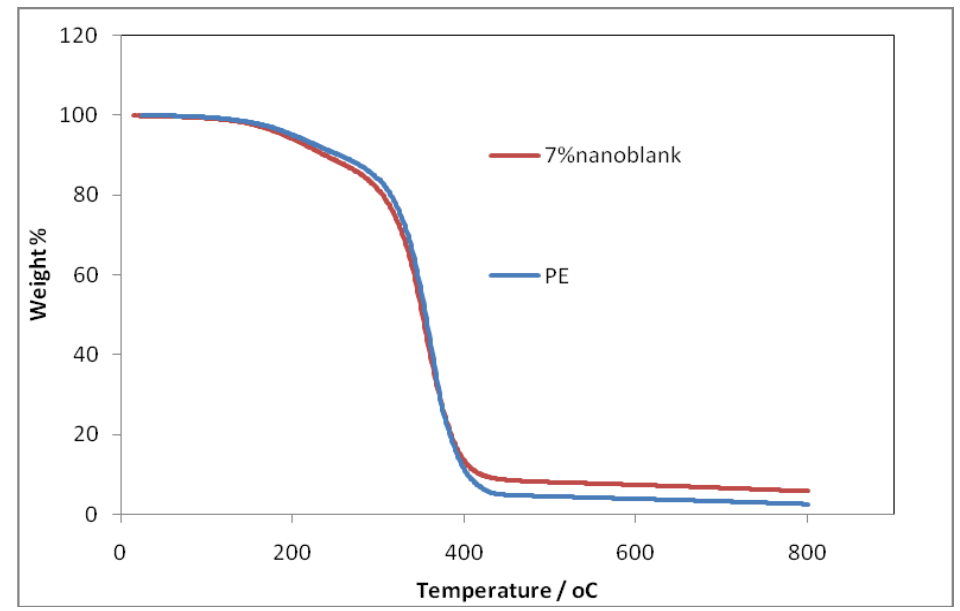

Fig 4: TGA of 7\% ODA-B. in PEEG1 matrix

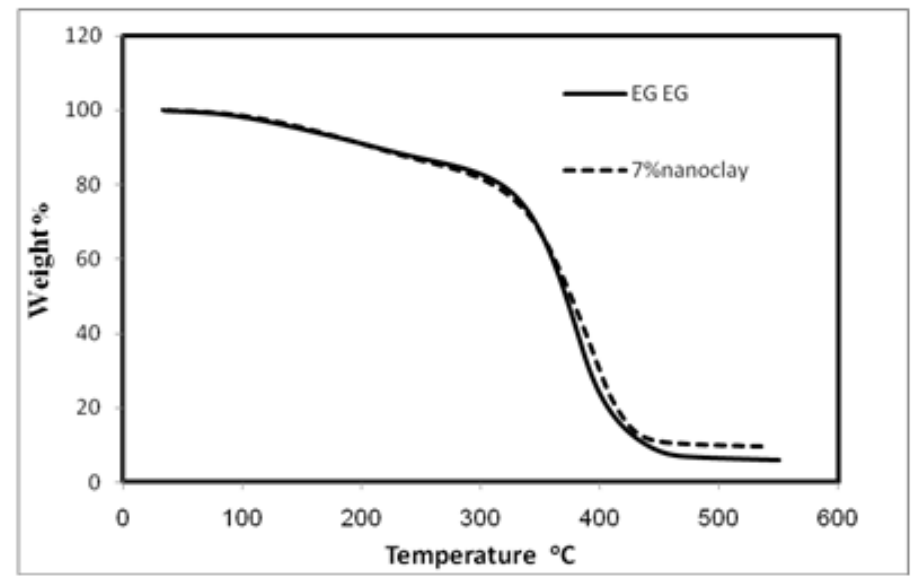

Fig 5: TGA of 7\% ODA-B. in PEEG2 matrix 
Table 1: properties of PEEG1/ODA \& PEEG2/ODA nanocomposites.

\begin{tabular}{|c|c|c|c|c|c|}
\hline \multirow[t]{2}{*}{ Sample code } & \multirow[t]{2}{*}{ Formulation } & \multirow{2}{*}{$\begin{array}{l}\text { Organoclay content / } \\
\text { gm }\end{array}$} & Thermal properties TGA & \multicolumn{2}{|c|}{ Mechanical properties } \\
\hline & & & Char yield \% & Tensile $\mathrm{N} / \mathrm{nm}^{2}$ & Elongation \% \\
\hline PEEG1 & $\mathrm{DMT}+\mathrm{EG}+\mathrm{MA}$ & 0 & 4.8 & 3.1 & 65.6 \\
\hline PEEG1 / 3\% & $\mathrm{DMT}+\mathrm{EG}+\mathrm{MA}$ & 0.66 & 4.9 & 6.3 & 10 \\
\hline PE EG1/ 5\% & $\mathrm{DMT}+\mathrm{EG}+\mathrm{MA}$ & 1 & 5 & 11.4 & 14.8 \\
\hline PEEG1 /7\% & $\mathrm{DMT}+\mathrm{EG}+\mathrm{MA}$ & 1.4 & 8.6 & 15.3 & 21.8 \\
\hline PEEG1 $/ 10 \%$ & DMT+EG+MA & 2 & 8.5 & 14.4 & 19.2 \\
\hline PEEG2 & $(\mathrm{DMT}+\mathrm{EG}+\mathrm{MA})+\mathrm{EG}$ & 0 & 7.6 & 1.8 & 69.1 \\
\hline PEEG 23\% & $(\mathrm{DMT}+\mathrm{EG}+\mathrm{MA})+\mathrm{EG}$ & 0.66 & 8.1 & 3.8 & 36.3 \\
\hline PEEG2 5\% & $(\mathrm{DMT}+\mathrm{EG}+\mathrm{MA})+\mathrm{EG}$ & 1 & 8.4 & 7.7 & 38.2 \\
\hline PEEG2 7\% & $(\mathrm{DMT}+\mathrm{EG}+\mathrm{MA})+\mathrm{EG}$ & 1.4 & 11 & 10.2 & 42.8 \\
\hline PEEG2 10\% & $(\mathrm{DMT}+\mathrm{EG}+\mathrm{MA})+\mathrm{EG}$ & 2 & 8.9 & 9.8 & 40.2 \\
\hline
\end{tabular}

\section{Mechanical Analysis}

In Fig 6a, b, the tensile strength of the PEEG2 nanocomposites is better than PEs nanocomposite owing to their higher degree of exfoliation and better adhesion at the PEEG1/ODA interface. Above 7\% B-ODA content, the tensile strength starts to decrease with OMMT content increase in both types of nanocomposites, due to a lower degree of exfoliation and a lower degree of polymer-MMT surface interactions at higher B-ODA content. Also, the cross-link density might be lower with a higher Na-EB content, leading to a lower tensile strength i.e. indicating that the crosslinking density is inversely proportional to the degree of exfoliation [34].

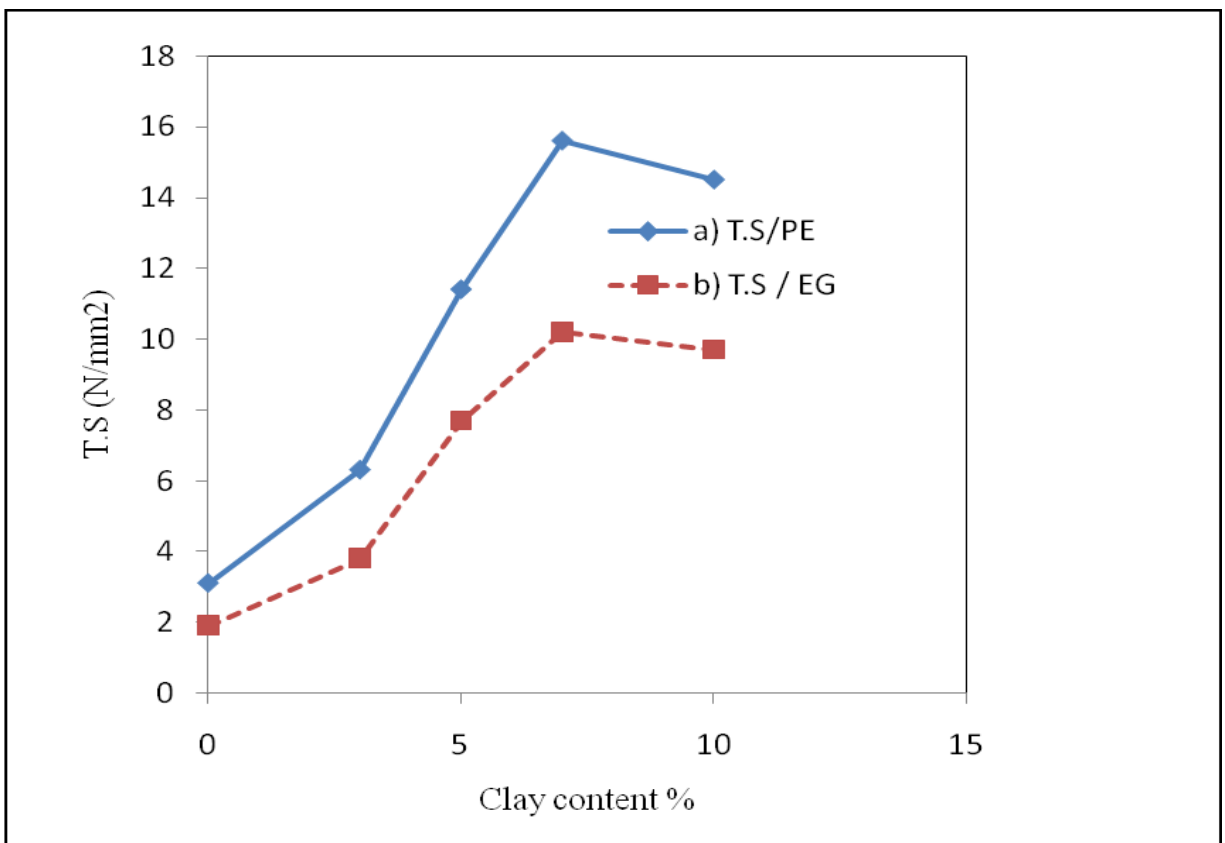

Fig 6: a) Tensile of different wt \% of ODA-B.0, 3, 5, and 10\% in PEEG1 matrix. b) Tensile of different wt \% of ODA-B.0, 3, 5, and 10\% in PEEG2 matrix.

The increase in tensile strength associated with increases in EB-ODA content is demonstrated in Table 1. It was evident that with the addition of small amount of montmorillonite $(3,5$ and $7 \%)$ to PEEG1, the tensile strength significantly increased. In Fig 7a, b, the elongation follows the same trend as tensile strength that is, increased with increasing EB-ODA contents up to 7\%. The results indicated the reinforcing effect of EB-ODA to enhance the mechanical properties of the nanocomposite. 


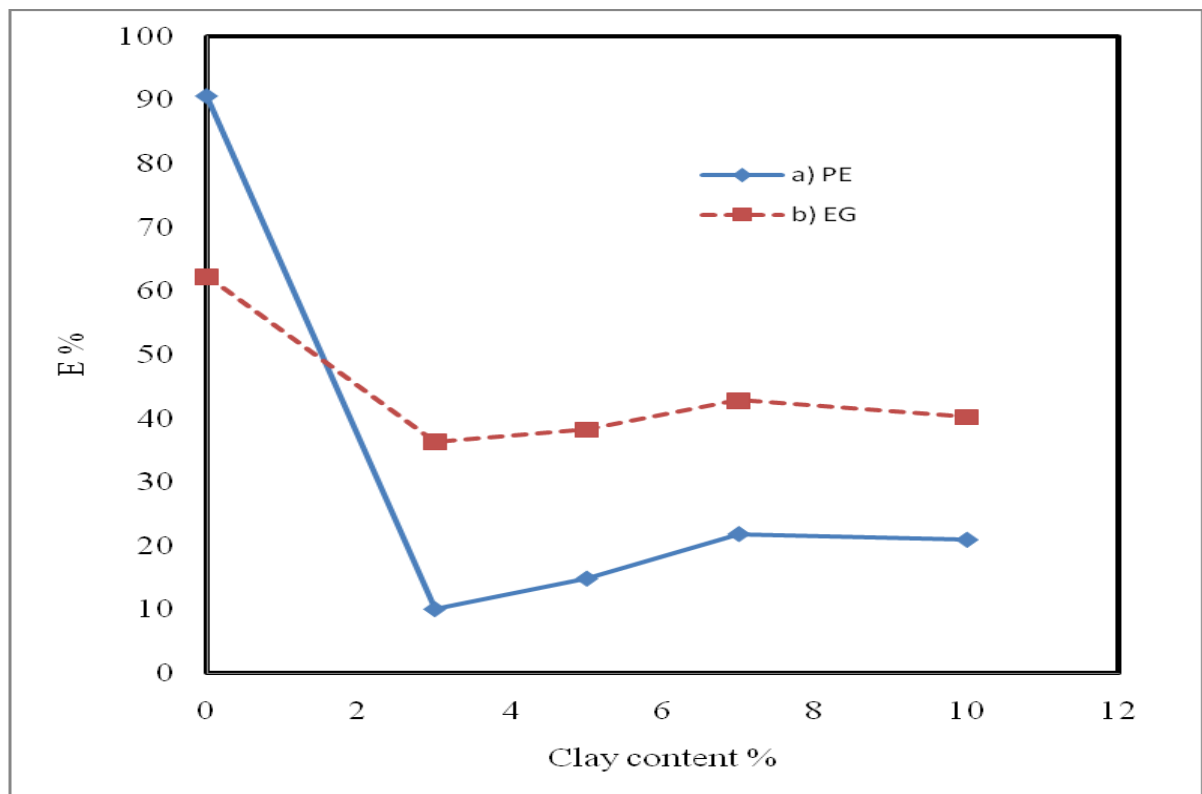

Fig 7. a) Elongation of different wt \% of ODA-B.0, 3, 5, and 10\% in PEEG1 matrix.

b) Elongation different wt $\%$ of ODA-B.0, 3, 5, and 10\% in PEEG2 matrix.

The hardness of nanocomposites and conventional clay filled composites is shown in Figs 8, 9. There is an increase in hardness value of nanocomposites compared to the pristine polyester. The nanosize clay platelets uniformly distributed in the matrix system effectively restrict indentation. No further improvement in hardness is noticed at higher clay content (i.e. 7 wt. \%). It may be due to the presence of porosity in the nanocomposites. During processing of nanocomposites at high clay contents, visually it was observed that the viscosity of the resin increases significantly. So the entrapped air during shear mixing finds very difficult to escape out of the matrix system and remains as micropores after curing. Another reason may be the formation of intercalated structure at high clay content, as is evident from the XRD results. This may lead to the formation of nanocomposite structure with two phases (hard phase where intercalated clay is present and soft phase where the matrix alone is present). There is no significant change in the hardness of conventional clay filled composites. The inorganic clay added just remains as microtactoids and does not contribute much on the hardness improvement.

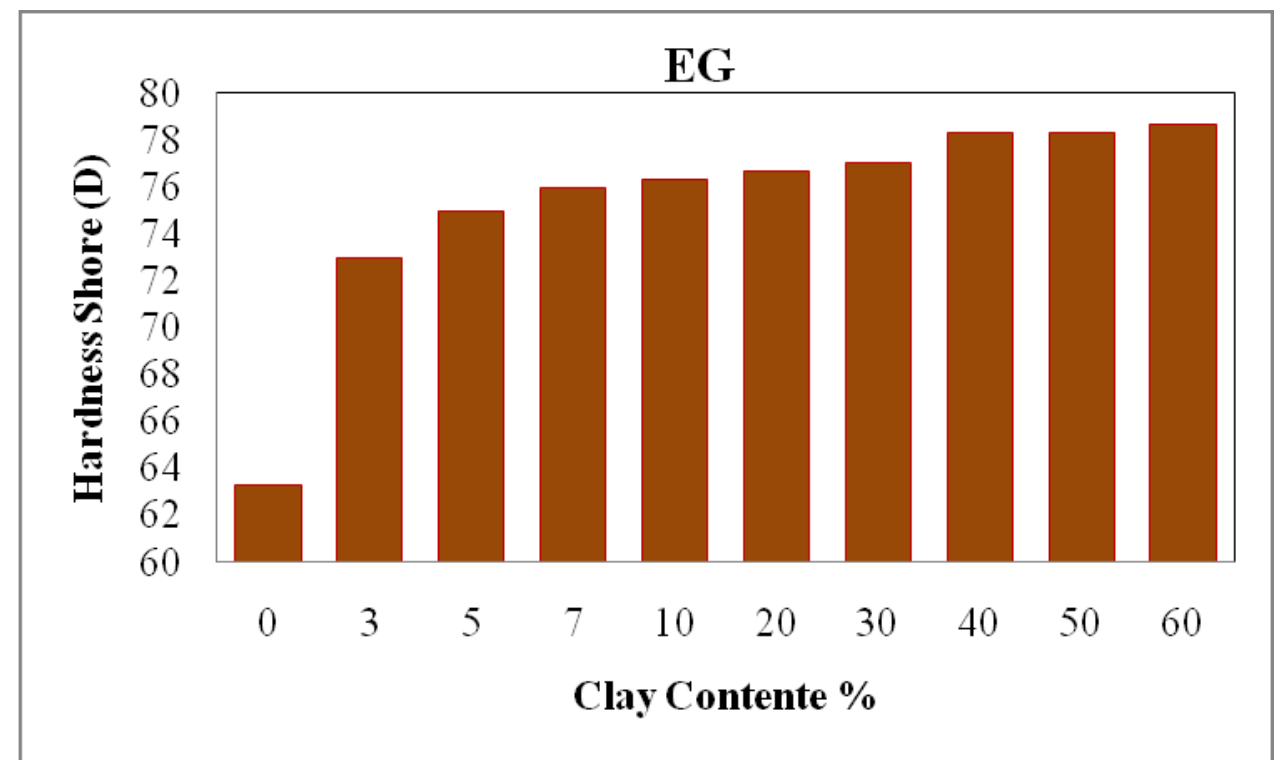

Fig 8: Hardness of different wt \% of ODA-B.0, 3, 5, 7, 10, 20, 30, 40, 50 and 60\% in PEEG2 matrix. 


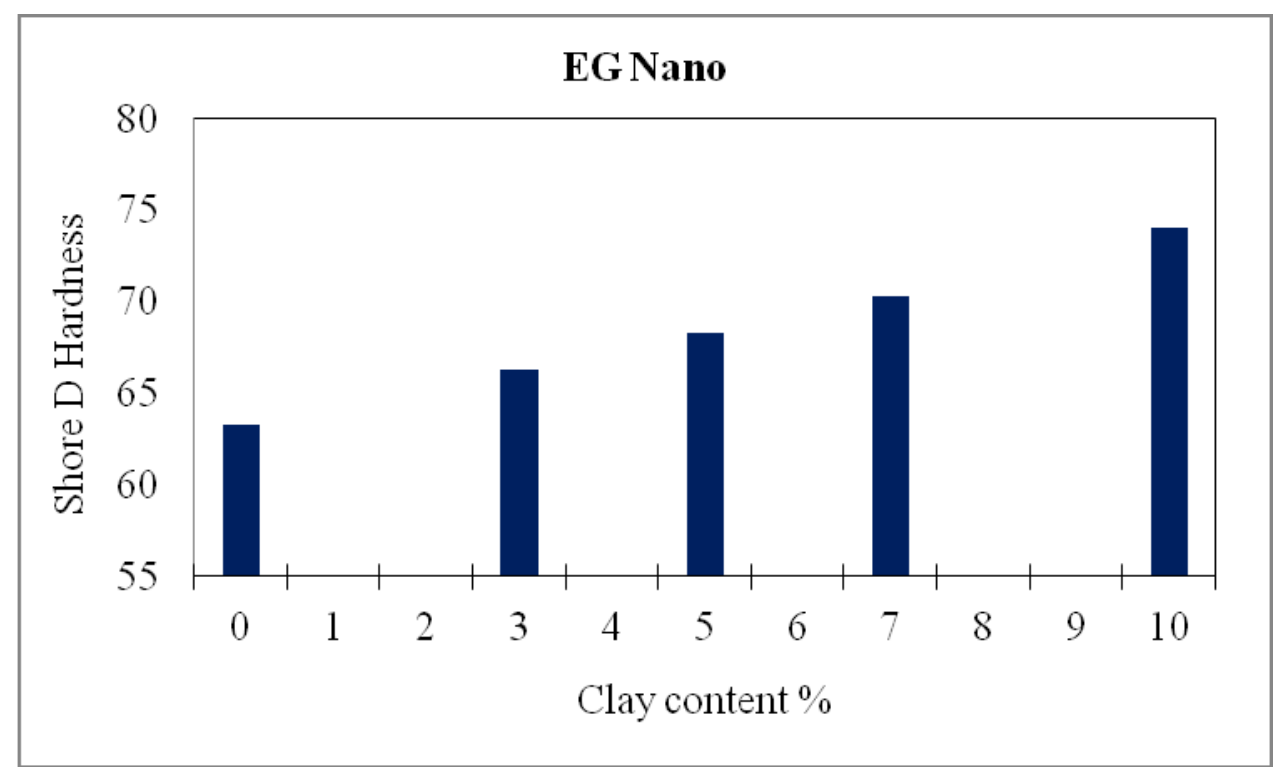

Fig 9: Hardness of different wt $\%$ of ODA-B.0, 3, 5, 7 and 10\% in PEEG2 matrix

Electrical Analysis According to the common used classification of the electrical conducting materials, the materials with electrical conductivity $\mathrm{r}$ lower than $10^{-6} \mathrm{Scm}^{-1}$ are treated as insulators, with electrical conductivity between $10^{-6} \mathrm{Scm}^{-1}$ and $10^{2} \mathrm{Scm}^{-1}$ as semiconductors, and consequently with $\mathrm{r}>10^{2} \mathrm{~S} \mathrm{~cm}^{-1}$ as metals. Thus, the nanocomposites of PEEG1, PEEG2 with organo clay (EB-ODA) presented in this work belong to materials characterized as semiconductors. For comparison it should be mentioned that pure PE, with $\mathrm{r}=$ $10 \_16 \mathrm{~S} \mathrm{~cm}^{-1}$ belongs clearly to insulating materials.

\section{Conclusion}

Polyesters (PEs) based on maleic anhydride and dimethylterephathalte with different concentrations of ethylene glycol EG were prepared to give two polyesters $\mathrm{PEEG}_{1}$ and $\mathrm{PEEG}_{2}$. Nanocomposites based on the prepared polyesters and organophilic Egyptian bentonite were prepared by sonicatore via in-situ procedure. The prepared organo-bentonite clay based on octadecylamine (ODA) was characterized with X-ray diffraction (XRD), and transmission electron microscopy (TEM). The results indicated that the intercalation of ODA within the clay layers. Organically modified clay was added in various contents (i.e. 3, 5, 7and $10 \mathrm{wt} \%$ ) to the prepared polyesters matrices to study the effect of nanosilicate on morphology. Furthermore, the XRD analysis revealed exfoliated and intercalated structures for PEEG1and PEEG2 nanocomposites respectively. TEM images provided evidence of nanoclay-PEs interaction. The influence of the organoclay content relative to micrometer clay on the prepared nanocomposites was analyzed through mechanical properties (i.e. tensile strength, elongation at break percentages and hardness shore D), electrical conductivity and thermal stability. All the modified clay-polyester nanocomposites displayed improved mechanical properties, with organoclay content up to $7 \mathrm{wt} \%$ as compared with PEs filled with micrometer clay $(40 \mathrm{wt} \%)$. The prepared nanocomposites exhibited improvement in conductivity and thermal stability. Beyond $7 \%$ wt organoclay deterioration in the properties of the nanocomposites takes place.

\section{References}

[1]. Mai YW, Yu Z-Z, 2006, Polymer nanocomposites: Woodhead publishing LTD.

[2]. Kojima Y, Usuki A, Kawasumi M, Okada A, Kurauchi T, Kamigaito O,1993, One-pot synthesis of nylon 6-clay hybrid. J Polym . Sci Part A Polym Chem, 31:1755-8.

[3]. Kawasumi M, 2004, The discovery of polymer-clay hybrids. J Polym Sci Part A Polym Chem, 42:819-24.

[4]. Fukushima Y, Inagaki S, 1987, Synthesis of an intercalated compound of montmorillonite and 6-polyamide .J Inclusion Phenom,5:473-82.

[5]. Kangoa S, Kaliab S, Celli A, Njugunad J, Habibie Y, Kumara R, 2013, Surface modification of inorganic nanoparticles for development of organic-inorganic nanocomposites-A review. Progress in Polymer Science, 38:1232- 1261.

[6]. Biasci L, Aglietto M, Ruggeri G, Ciardelli F, 1994, Functionalization of montmorillonite by methyl methacrylate polymers containing side-chain ammonium cations. Polymer, 35(15):3296-309.

[7]. Huang S X, Lewis, Brittain WJ, 2000, Synthesis of Polycarbonate-Layered Silicate Nanocomposites via Cyclic Oligomers. Macromolecules, 33:2000-2004.

[8]. Choudalakis G, Gotsis AD, 2009, Permeability of polymer/clay nanocomposites: a review. Eur Polym J, 45:967-84.

[9]. Albrecht M, Ehrler S, Muhlebach A, 2003, Nanocomposites from layered silicates: Graft polymerization with intercalated ammonium peroxides. Macromol Rapid Commun, 24: 382-387.

[10]. Kiersnowski A, Piglowski J, 2004, Polymer-layered silicate nanocomposites based on poly( $\varepsilon$-caprolactone), Eur Polym J, 40:1199207. 
[11]. Ray AS, Okamoto M, 2003, Polymer/layered silicate nanocomposites: a review from preparation to processing. Prog Polym Sci, 28:1539-641.

[12]. Hussain F, Hojjati M, 2006, polymer-matrix nanocomposites, processing, manufacturing, and application: an overview. J Compos Mater, 40(17):1511-65.

[13]. Lagaly G. 1999, Introduction: from clay mineral-polymer interactions to clay mineral-polymer nanocomposities. Appl Clay Sci, $15: 1-9$

[14]. Takahashi S, Goldberg HA, Feeney CA, Karim DP, Farrell M, O’Leary K, 2006, Gas barrier properties of butyl rubber/vermiculite nanocomposite coatings. Polymer, 47:3083-93.

[15]. Suh DJ, Lim YT, Park OO, 2000, The property and formation mechanism of unsaturated polyester-layered silicate nanocomposite depending on the fabrication methods. Polymer, 41: 8557-8563.

[16]. Beheshty MH, Vafayan M, Poorabdollah M, 2009, Low Profile Unsaturated Polyester Resin-Clay Nanocomposite Properties. Polym. Compos, 30:629-638.

[17]. Karikal CC, Muthukaruppan A, Josephine SR, Periyannan G, 2007, Thermo mechanical behaviour of unsaturated polyester toughened epoxy-clay hybrid nanocomposites. J Polym Res, 14:319-328.

[18]. Dhakal HN, Zhang ZY, Richardson MOW , 2006, Nanoindentation behaviour of layered silicate reinforced unsaturated polyester nanocomposites.. Polymer Testing ,25:846-852.

[19]. Kedzierski M, Pneczek P, 2004, Unsaturated polyester/montmorillonite nanocomposites prepared by in situ intercalative copolyaddition. Polymer, 49:11-12.

[20]. Liqun Xu, JamesL L,2005, Kinetic Analysis and Mechanical Properties of Nanoclay Reinforced Unsaturated Polyester (UP) Resins Cured at Low Temperatures. POLYM. ENG. SCI., 45:496-509.

[21]. Kim HG, Oh DH, Lee HB, Min KE, 2004, Effect of Reactive Diluents on Properties of Unsaturated Polyester/Montmorillonite Nanocomposites. J Appl Polym Sci 92: 238-242.

[22]. Liqun $\mathrm{Xu}$, Lee LJ,2004, Effect of nanoclay on shrinkage control of low profile unsaturated polyester (UP) resin cured at room temperature. Polymer, 45:7325-7334.

[23]. Miyagawa H, MohantyAK, Burgueo R, Drzal LT, Misra M, 2006, Characterization and Thermophysical Properties of Unsaturated Polyester-Layere Silicate Nanocomposites. Journal of Nanoscience and Nanotechnology, 6: 464-471.

[24]. Ollier R, Rodriguez E, Alvarez V, 2013, Unsaturated polyester/bentonite nanocomposites: Influence of clay modification on final performance, 48:137-143.

[25]. Chieruzzia M, Miliozzib A, Kennya JM, 2013, Properties of unsaturated polyester/clay nanocomposites, 45:44-48.

[26]. Zhou Y, Yang X, Jia D, 2007, Cure behavior of unsaturated polyester/modified montmorillonite nanocomposites. Polym Int, $56: 267-274$

[27]. Kim YH, Kim DS, 2008, Effects of organic modifications of clay on the ultraviolet-curing behavior and structure of a polyesteracrylate/clay nanocomposite system.Polym. Adv. Technol, 19: 1236-1241.

[28]. Inceoglu BA, Yilmazew U, 2003, Synthesis and Mechanical Properties of Unsaturated Polyester Based Nanocomposites. Polymer Engineering and Science ,43: 661- 669

[29]. Motawie AM, Madany MM, El-Dakrory AZ, Osman, HM, Ismail EA, Badr MM, El-Komy DA, Abulyazied DE, 2014, PhysicoChemical Characteristics of Nano-organo Bentonite Prepared Using Different Organo-Modifiers Egyptian Journal of Petroleum (EGYJP), 23: 3 .

[30]. Alexandre M, Dubois P, 2000, Polymer-layered silicate nanocomposites; preparation, properties and uses of a new class of materials. Mater Sci Eng R, 28(1/2):1-63.

[31]. Morgan AB, Gilman JW, 2003, Characterization of polymer-layered silicate (clay) nanocomposites by transmission electron microscopy and X-ray diffraction: a comparative study. J Appl Polym Sci, 87:1329-38.

[32]. Porter D, Metcalfe E, Thomas MJK, 2000, Nanocomposite fire retardants- a review. Fire Mater, 24:45-52.

[33]. Ma J, Xu J, Ren J-H, Yu Z-Z, Mai Y-W, 2003, A new approach to polymer/ montmorillonite nanocomposites. Polymer, 44:461924.

[34]. Kommann X, Berglund L, Sterte J, Giannelis EP, 1998, Nanocomposites based on montmorillonite and unsaturated polyester. Polym. Eng. Sci, 38(8):1351-1358. 